p. 213). The same subject has now been further investigated by $\mathrm{Mr}$. D. Lloyd-Jones (Journ. Experimental Zoology, vol. xviii., No. 3) in a microscopical and chemical study of the feather-pigments. Red colour is due to red-brown pigment-granules which are present in the intermediate cells of the epidermis as well as in special pigment-cells. This pigment, if very finely divided, produces yellow. Black pigment under various conditions produces black, dun, blue, or silver.

Pigeons serve also as the subject of an inquiry into "Sex Ratios" by Drs. L. J. Cole and W. F. Kirkpatrick (Rhode Island Agric. Exp. Station, Bulletin 162). The normal ratio calculated from a large number of broods is 105 males to roo females, and the death-rate is especially high for the first three days after hatching and at the age of about a fortnight. It is well known that the pigeon's normal brood consists of two eggs. In the recorded cases there were 284 bisexual broods to 302 unisexual; of the latter I 49 consisted of two males and ${ }_{5} 53$ of two femalesa result indicating almost perfect equality. The deathrate of males and females in the bisexual broods is essentially equal. "A comparison of the numbers of each sex hatched from first and from second eggs respectively shows no tendency for the former to produce exclusively males and the latter females, but more males than females are hatched from both." The authors conclude that "sex in pigeons is determined according to the laws of chance"-in Mendelian terminology the individuals of one sex are heterozygous, and those of the other homozygous as regards the sexdetermining factors.

G. H. C.

\section{BIOMETRICS AND MAN.}

I $\mathrm{N}$ part iv. of vol. x. of Biometrika, Mr. H. Waite publishes an interesting study, based on two thousand complete sets of finger-prints of adult males, part of a series in the biometric laboratory, University College, London. It appears that the various types of finger-print are not scattered at random over the fingers; certain types are more or less peculiar to certain fingers, and the appearance of one type is associated with that of another. In this respect certain fingers are more closely related to each other than to any third finger, and the distribution of this relationship is in general similar to that of the correlations of the bones of the same fingers. In the same number, Dr. Alice Lee discusses the influence of segregation on tuberculosis, a question to which much attention has been devoted of recent years. No method of measuring the extent of segregation is, however, found satisfactory, and the various methods used, for example, by Dr. Newsholme, lead, when examined by more stringent methods, to contradictory and inconclusive results. Whether there is any really substantial relation between the prevalence of phthisis and institutional segregation may remain an open question, but Dr. Lee is of opinion that no such relation has been demonstrated. Miss Elderton and Prof. Pearson similarly fail to find any evidence that isolation reduces the attack-rate from diphtheria; no appreciable influence on the attack-rate is found in certain data placed at their disposal by the medical officer of health for Coventry, though the death-rate may be lowered.

In the same journal Prof. Pearson, in collaboration with Miss Elderton, contributes an important memoir on further evidence of natural selection in man. The variate-difference correlation method is applied to the death-rates for males and for females in England and Wales from 1850 to I908. The correlation between death-rates for successive years of life, over a long NO. 2389 , VOL. 95] series of years, is high and positive. But the correlation of first differences is negative, and this negative correlation increases in intensity as higher and higher differences are taken, until fairly steady values are reached for the sixth differences, ranging round -0.7 . Thus for males the correlation of sixth differences in the first and second years of life is -0.688 , in the fourth and fifth years of life -0.695 . For females the corresponding figures are -0.719 and -0.736 . The correlations in each case are taken between death-rates of those born in the same year. At an interval of two years the partial correlations are negative but much lower; at three and four years' interval the signs are irregular and the results inconclusive. To assert the existence of selection and measure its intensity, the authors remind their readers, must be distinguished from advocacy of a high infantile mortality as a factor of racial efficiency.

We can only briefly direct attention to two articles by $\mathrm{Mr}$. R. A. Fisher on the frequency distribution of the correlation coefficient in samples from an indefinitely large population, and on the distribution of standard derivations of small samples.

\section{REPORTS ON MINING INDUSTRIES.}

TWO reports issued by the Canadian Department of Mines ("Peat, Lignite, and Coal," by B. F. Haanel; "Report on the Non-Metallic Minerals Used in the Canadian Manufacturing Industries," by Howells Frechette; Ottawa, I9I4) are further examples of the sedulous care with which the Canadian Government is endeavouring to foster the industry of mining in the Dominion. The report upon peat, lignite, and coal deals exclusively with the application of these fuels to the generation of power-gas and to the recovery of by-products, the latter being chiefly ammoniacal salts. An elaborate study has been made of the various methods of dealing with peat in Europe, although, for some reason not easy to understand, Russian practice appears not to have been included, in spite of the fact that conditions in Russia resemble more closely those in Canada than do any of the other countries investigated. The first part of the report is taken up with a discussion of the various methods of producing peat fuel; it is interesting to note that the author has devoted a good deal of attention to the well-known Ekenberg process of wet carbonisation, and that his conclusions are decidedly unfavourable to the process. He points out that the most recent report on the subject by Lassen shows "that in continuous operation on a large scale, a moisture content below $7^{\circ}$ per cent. in the pressed cake cannot be counted on," and dismisses the subject with the following statement:-

"Although large funds have been placed at the disposal of various investigators in order to enable them to demonstrate the economic value of the process, and although a private company has conducted elaborate experiments on a large scale, involving the expenditure of a large amount of money, not one ton of peat fuel has been manufactured on a commercial scale by means of this process."

The author's opinion of the Brune and Horst process for pressing out the water is equally unfavourable, nor is he greatly impressed by the possibilities of any of the methods of artificial drying, and sums up in favour of air-dried peat. He shows that under normal Canadian conditions peat can be utilised to advantage for the production of gas provided that it contains not more than 40 per cent. of moisture and that it can be obtained at a cost not exceeding $1.5^{\circ}$ dollars $(6 s .3 d$.) per ton of peat containing 30 per cent. of moisture. He holds 
that the recovery of ammonia is not likely to be profitable unless the nitrogen content exceeds $I \frac{1}{2}$ per cent. calculated upon absolutely dry peat. Finally, he shows that under favourable conditions power can be generated from certain of these Canadian peat bogs at a cost equal to or below that at which it can be obtained by the utilisation of water-power. A little attention is also devoted to the question of the utilisation of the lignites of certain of the Western Provinces, where true bituminous coal is not obtainable locally, and it is shown that in certain circumstances it too can be employed profitably in the generation of gas.

The second report is intended to aid, not only the mining industry, but also the very large number of manufacturing industries that depend to a greater or lesser extent upon an adequate supply of raw materials in the shape of mineral products. The report deals with a very large number of miscellaneous minerals, of which asbestos, barytes, clay, lime, and sand are perhaps the most important, and it should be noted that such minerals as are used in Canadian manufactures but are not produced in Canada are referred to, as well as the minerals of domestic production. It is noteworthy that quite a considerable quantity of minerals is imported, although they could be produced in the Dominion, and one of the main objects of this report is to bring actual or possible producers and consumers into closer touch with one another. The object is an excellent one, and such reports as this should prove of the greatest value to both parties and should help towards that very desirable object, the industrial independence of this great Dominion.

The report of the Chief Inspector of Mines of the State of Mysore for the year I9I3 has just been issued. Apart from the statistical portion, which shows that the value of the bullion produced during the year in question was $2,150,193 l$, , a decrease of 0.37 per cent. from the previous year, the chief general interest in this report is to be found in a careful investigation of a shaft accident at the Mysore Gold Mine. It appears that the steel pin, which secured a driving clutch, that connected the engine shaft and the winding reel suddenly broke, allowing the cage, in which forty-two miners were travelling, to fall to the bottom of the shaft. An investigation was held into the cause of the fracture of this pin and into the reason why the powerful brake attached to the winding engine did not hold the reel, and the report of the committee of inquiry is now given. It cannot be said that the cause of the fracture is satisfactorily explained, but the insufficiency of the braking arrangements is very clearly demonstrated. Having regard to the fact that this brake is of the construction that is in general use on winding engines in all parts of the world, this report deserves the careful attention of all who have to do with winding from deep shafts by means of the powerful winding engines that are in general use in modern mines; in particular it may be noted that the brake appears to have complied fully with the provisions of our Coal Mines Act, and yet was found inadequate to prevent the very serious accident in question.

Another interesting section in this report deals with accidents due to "air blasts," which caused no fewer than thirty-one deaths during the vear in question. These air-blasts consist in the sudden fiying-off of huge masses of rock from the walls of stoped-out portions of the deposit, the action being extremely violent and suggesting that the rock is under some condition of great strain that suddenly relieves itself. The phenomenon is as yet but little understood, and all measures taken for combating this danger are still of a more or less tentative character.
TRYPANOSOMES CAUSING DISEASE IN MAN AND DOMESTIC ANIMALS IN CENTRAL AFRICA. ${ }^{1}$

THESE lectures are confined to a consideration of the trypanosomes causing disease in man and domestic animals in Central and Southern Africa. The conditions, however, which obtain on the east and west coasts of Africa between $20^{\circ} \mathrm{N}$. and $30^{\circ} \mathrm{S}$. latitude are much the same as those which are found in the central parts, and it is probable that the same trypanosome species are found throughout. So that in describing the species found in our own colonies it may be assumed that all the important pathological species found in Central Africa are being dealt with, although in other places they may be known by other names.

The central region-the tropical or equatorial-corresponds with the distribution of the tsetse-flies, and the trypanosomes causing disease in this region are carried from sick to healthy animals by various species of this genus of flies. In the north of Africa, outside the range of the tsetse-flies, two trypanosome diseases are found, one of the horse (dourine), and another of camels (surra), the former conveyed from sick to healthy horses by contagion, the latter almost certainly by large biting flies, the so-called horse-flies, or tabanidæ.

\section{Classification of the African Trypanosomes.}

The three characters mainly relied upon in this classification of trypanosomes are, in the first place, their morphology; secondly, their pathogenic action on animals; and, thirdly, their mode of development in the tsetse-flies. They may be divided into three groups, and these are set out in the following scheme :-

\section{Group A. Trypanosoma Brucei Group. \\ I. Trypanosoma brucei. \\ 2. Trypanosoma gambiense. \\ 3. Trypanosoma evansi. \\ 4. Trypanosoma equiperdum.}

Group B. Trypanosoma Pecorum Group.

I. Trypanosoma pecorum.

2. Trypanosoma simiae.

Group C. Trypanosoma Vivax Group.

r. Trypanosoma vivax.

2. Trypanosoma caprae.

3. Trypanosoma uniforme.

These names probably represent most of the principal pathogenic trypanosomes discovered up to the present time in Africa. The northern species, Trypanosoma evansi and T. equiperdum, are placed in the first group, as they seem by morphology and their action on animals to belong there. Each group is distinguishable or separable by well-defined characters.

Group A. The Trypanosoma brucei Group.-The species forming this group (Fig. I) are all more or less polymorphic, varying in size and shape from short and stumpy forms without free flagella to long and slender forms with free flagella. The cytoplasm contains numerous dark-staining granules. The micronucleus or kinetonucleus is small, and is situated as a rule some distance from the posterior extremity. The undulating membrane is well developed and thrown into bold folds.

1 Abridged from the Croonian Lectures delivered before the Royal College of Physicians of London on June $17,22,24$, and 29, by Sir David Bruce, C.B., F.R.S.

No. 2389 , VOL. 95] 